\title{
Positioning Aeromonas Infection in Inflammatory Bowel Disease: A Retrospective Analysis
}

\author{
Tiago Pereira Guedes $^{\mathrm{a}}$ Joana Alves Silva ${ }^{\mathrm{a}}$ Sara Neves $^{\mathrm{b}}$ Daniela Falcão ${ }^{\mathrm{a}}$ \\ Paula Costa ${ }^{c}$ Paula Lago a Isabel Pedroto ${ }^{a}$ Marta Salgado ${ }^{a}$ \\ ${ }^{a}$ Gastroenterology Department, Centro Hospitalar Universitário do Porto, Porto, Portugal; ${ }^{b}$ Infectious Diseases \\ Department, Centro Hospitalar Universitário do Porto, Porto, Portugal; ' ${ }^{\mathrm{N}}$ Microbiology Department, Centro \\ Hospitalar Universitário do Porto, Porto, Portugal
}

\section{Keywords}

Aeromonas · Inflammatory bowel disease · Crohn's disease · Ulcerative colitis · Gl infections · Immunology . Microbiology and inflammatory bowel disease

\begin{abstract}
Background and Aim: Aeromonas are Gram-negative rods known to cause a spectrum of diseases. Inflammatory bowel disease (IBD) is an idiopathic complex condition resulting from interaction of multiple factors. Aeromonas infection in association with IBD is still largely unknown. We aim to look for the significance of Aeromonas infection and for significant differences between IBD and non-IBD patients. Methods: A retrospective observational analysis was performed of all patients positive for Aeromonas in stool cultures, during a 10-year period, from a tertiary and university hospital. Results: Fifty patients were included, 56\% male with a mean age of 42.1 years. Thirty-eight (76\%) were non-IBD and 12 (24\%) IBD patients. IBD patients were more frequently under immunosuppressors. Two patients were asymptomatic and $44 \%$ developed mild, $44 \%$ moderate, and $16.7 \%$ severe infection. The main strains isolated were Aeromonas hydroph-
\end{abstract}

ila/caviae. Bacterial co-isolation was found in 4 non-IBD and histological findings of cytomegalovirus in 2 IBD patients. Non-IBD patients presented more frequently with fever and IBD patients with bloody diarrhea and abdominal pain. There was higher tendency for severe infection rate in IBD patients with higher antimicrobial therapy use. Steroids were exclusively used in the IBD group. From IBD, 4 patients had the diagnosis of ulcerative colitis and 9 of Crohn's disease with colonic involvement. Of these patients, 5 received IBD diagnosis after the acute episode of Aeromonas infection. Conclusions: Clinical presentation of Aeromonas infection differs between IBD and non-IBD patients. Non-IBD patients had milder severity of infection with less use of antibiotics. Aeromonas infection seems to greatly contribute to IBD manifestation.

(C) 2021 Sociedade Portuguesa de Gastrenterologia Published by S. Karger AG, Basel

Tiago Pereira Guedes and Joana Alves Silva contributed equally to this work (co-first authors).

\section{(c) 2021 Sociedade Portuguesa de Gastrenterologia} Published by S. Karger AG, Basel

This is an Open Access article licensed under the Creative Commons Attribution-NonCommercial-4.0 International License (CC BY-NC) (http://www.karger.com/Services/OpenAccessLicense), applicable to the online version of the article only. Usage and distribution for commercial purposes requires written permission.
Correspondence to:

Tiago Pereira Guedes, tiagoapguedes@gmail.com 
Infeção por Aeromonas e doença inflamatória intestinal: uma análise retrospetiva

\section{Palavras Chave}

Aeromonas · Doença inflamatória intestinal · Doença de Crohn · Colite ulcerosa · Infeção gastrointestinal · Imunologia Microbiologia e doença inflamatória intestinal

\section{Resumo}

Introdução: A etiologia da Doença Inflamatória Intestinal (DII) é complexa e resultante da interação de diversos fatores, nomeadamente microbiológicos. A infeção por Aeromonas caracteriza-se por um espectro alargado de manifestações clínicas. O papel da infeção por Aeromonas na DII não está caracterizado. Objetivos: Avaliar o significado da infeção por Aeromonas na DIl e as diferenças com a infeção em doentes não-DII. Métodos: avaliação retrospetiva e observacional de todos os doentes com isolamento microbiológico de Aeromonas em amostras fecais num período de 10 anos, num hospital terciário. $\operatorname{Re}$ sultados: foram avaliados 50 doentes, $56 \%$ do sexo masculino, com idade média de 42.1 anos. Doze (24\%) com diagnóstico de DII e trinta e oito (76\%) não-DII. Os doentes com DII encontravam-se mais frequentemente sob imunossupressão. Dois doentes foram assintomáticos, $44 \%$ desenvolveram doença ligeira, $44 \%$ moderada e $16.7 \%$ severa, havendo maior tendência para infeção severa nos DII. Os doentes não-DII apresentaram mais frequentemente febre e os DII diarreia sanguinolenta e dor abdominal. O uso de antimicrobianos foi superior no grupo DII e a utilização de corticoesteroides foi exclusiva nestes doentes. Isolamento concomitante de outros agentes microbiológicos ocorreu em 4 doentes não-DII e 2 com DII tinham histologia compatível com infeção por Citomegalovírus. Da população DII, 4 eram Colite Ulcerosa e 9 Doença de Crohn com envolvimento cólico. Destes, 5 receberam o diagnóstico após a infeção por Aeromonas. Conclusão: A apresentação clínica da infeção por Aeromonas foi distinta entre as populações DII e não-DIl, sendo que os doentes DIl apresentaram doença mais severa e maior utilização de antimicrobianos. A infeção na DIl ocorreu essencialmente em doentes com envolvimento cólico.

(c) 2021 Sociedade Portuguesa de Gastrenterologia Published by S. Karger AG, Basel

\section{Introduction}

The Aeromonas genus, belonging to the Aeromonadaceae family, comprises facultatively anaerobic Gram-negative bacteria widely present in aquatic environments, soil, and food goods (such as meat, shellfish, and dairy products), making the gastrointestinal tract an understandable reaching point for Aeromonas $[1,2]$. However, there has been discordant information concerning its role as a gastrointestinal pathogen, since its isolation in stool from asymptomatic individuals is not uncommon [3]. Of the 17 phenospecies of the genus Aeromonas, the most frequently isolated from human feces are A. hydrophila, A. caviae, A. veronii, and A. trota [4-6]. The most common manifestation of Aeromonas infection is diarrhea, usually acute and self-limited, but other presentations such as bloody diarrhea and abdominal pain, or chronic more indolent diarrhea, have been described [7]. Although most of the infections occur in immunocompromised patients, it can also cause disease in healthy individuals [8].

Although the ultimate cause of inflammatory bowel disease (IBD) is still unknown, there are many components interacting in its network of pathogenic mechanisms like environmental factors, genetic susceptibility, dysregulated immune response, and microbiological factors $[9,10]$. Regarding the latter, both alterations in intestinal microbiota and infections by external agents might play a role in IBD onset and its flares $[11,12]$. Dysbiosis can also result from commensal flora that, although normal in speciation, possess more subtle virulence factors such as enteroadherence, or the lack of diversity of the fecal microbiome $[13,14]$.

Considering the specific bacteria related to IBD onset, Campylobacter is probably the one with more data, while the heterogeneity of the studies does not allow to draw consistent conclusions [15]. Although data are mainly based on case report studies, some authors have suggested that Aeromonas can be a trigger of flares in IBD [1618 ] and as well as a trigger to develop de novo chronic colitis in patients with no previous history of $\operatorname{IBD}[7,19]$. To our knowledge, only 2 recent studies involving IBD patients have tried to correlate the diagnosis and severity of the disease with Aeromonas infection [7, 8].

Our aim was to further look for the significance of Aeromonas infection as well as for significant differences between IBD and non-IBD patients. 


\section{Materials and Methods}

Patients and Clinical Information

A retrospective analysis of data was performed of inpatients and outpatients with a positive stool culture for Aeromonas, between January 2009 to January 2019, in a tertiary and university hospital. Patients of all ages were included. Clinical data were obtained retrospectively from the electronic medical records.

Baseline data included age at Aeromonas fecal detection, sex, comorbidities (namely the presence of IBD and transplantation status), ongoing drugs (namely immunosuppressants), recent travels, and previous abdominal surgery. Clinical characteristics at the time of Aeromonas detection were also analyzed: the presence of symptoms attributed to gastrointestinal infection such as nausea, vomiting, diarrhea, number of bowel movements, abdominal pain, and fever; endoscopy findings, if performed; presence of histopathological features of cytomegalovirus (CMV) infection in colon biopsies; other bacterial co-identification in stool cultures; treatment applied (namely antibiotics and steroids); disease severity and/or death related to the infection.

The indication for treatment was done according to the physician's criteria. Disease severity was defined as: (a) mild self-limited gastroenteritis, as a gastrointestinal infection that resolved spontaneously without the need for antibiotics; (b) moderate gastroenteritis, as a gastrointestinal infection that required antibiotic treatment; and (c) severe gastroenteritis, defined by a gastrointestinal infection complicated with septicemia and/or renal impairment. Death related to the infection was defined as the occurrence of death over the duration of infection and/or antibiotic therapy.

Stool samples were processed for bacterial culture using GN broth and selective media: Macconkey agar, Macconkey agar with sorbitol, Salmonella-Shigella agar, CIN (Cefsulodin-Irgasan-Novobiocin) agar, and Campylosel agar. In certain patients, a blood agar with an ampicillin disc was also used. The culture media were incubated at $35^{\circ} \mathrm{C}$ and observed daily for $48 \mathrm{~h}$, except for the Campylosel media. Suspected colonies of Aeromonas spp. in CIN media and those that grew close to the ampicillin disc and, simultaneously, showed a positive oxidase reaction, were identified. The identification was made in automated systems: phenotypical methods (Vitek $2^{\circledR}$ - bioMérieux) or by mass spectrometry technique (MALDI-TOF MS ${ }^{\circledR}$ - bioMérieux).

\section{IBD and Non-IBD Patients}

Data from all patients was analyzed, and two groups (IBD and non-IBD patients) were created for comparison. The IBD group included all patients with the diagnosis of IBD previously and after Aeromonas isolation. Individuals for whom both ulcerative colitis (UC) and Crohn's disease (CD) were recorded on successive dates were categorized according to the latest.

\section{Statistical Analysis}

Descriptive analysis was performed considering absolute and relative frequencies for categorical variables or mean and standard deviation for quantitative variables. Association between qualitative variables was performed based on the $\chi^{2}$ test (with Yates' correction) or Fisher' exact test (when assumptions could not be verified in $2 \times$ 2 tables). Group comparison according to quantitative variables was performed using the independent-sample $t$ test or Mann-Whitney test (variable with relevant skewness). In all analyses, a significance level of 0.05 was considered and SPSS version 26 was used.

\section{Results}

\section{Baseline Characteristics}

Stool isolation of Aeromonas was identified in 53 patients during the 10-year period of the study. Fifty patients were included and analyzed. Three were excluded due to the absence of minimal clinical information.

Our population consisted mainly of individuals of male sex $(54 \%)$ with a mean age of 42.1 years (1-89 years old). Fourteen (28\%) patients were under 18 years old. Baseline characteristics are presented in Table 1.

Twelve patients (24\%) had the diagnosis of IBD, with 7 (14\%) having it diagnosed previously and 5 (10\%) after Aeromonas fecal isolation. Five patients had ongoing chemotherapy treatment during Aeromonas isolation and 2 had advanced liver disease. Thirteen patients (26\%) were immunosuppressed considering therapeutics as calcineurin inhibitors, AZA, systemic steroids, and biological therapy as infliximab. Six patients (12\%) were previously submitted to organ transplantation. At the time of Aeromonas isolation, 4 patients were under azathioprine (AZA), 6 under topical or systemic steroids, and 6 under calcineurin inhibitors. Only 1 IBD patient was under combined therapy with infliximab and AZA. Only 1 nonIBD patient was under AZA for autoimmune hepatitis. Also, the only IBD patient under calcineurin inhibitors was a liver transplant recipient.

No patient had recent travel history. Twelve patients (24\%) presented a history of previous abdominal surgery, with 3 having a previous hemicolectomy, 1 a cholecystectomy, 3 liver transplants, 1 reno-pancreatic transplant, and 2 gastric bypasses.

\section{Clinical Presentation in IBD and Non-IBD Patients}

The clinical and microbiological characteristics at the time of Aeromonas isolation are shown in Table 2. From the overall sample, $48 / 50$ (96\%) patients were found to have symptoms that could be attributed to the presence of Aeromonas. Only 1 IBD and 1 non-IBD patient were considered asymptomatic: concerning the IBD patient, the stool culture was required in the course of the diagnosis of IBD, as part of a protocol required at the first consultation. This patient was sent to IBD consultation due to chronic diarrhea and abdominal pain in the past year but was asymptomatic at the time of consultation. Concerning the non-IBD patient, the stool culture was required in the course of the postrenal transplantation protocol.

The most frequent strains isolated in both groups were A. hydrophila/caviae (distinction not possible with the 
Table 1. Baseline characteristics

\begin{tabular}{|c|c|c|c|c|}
\hline & $\begin{array}{l}\text { Total } \\
n(\%) \text { or mean (SD) }\end{array}$ & $\begin{array}{l}\text { IBD } \\
n(\%) \text { or mean (SD) }\end{array}$ & $\begin{array}{l}\text { Non-IBD } \\
n(\%) \text { or mean (SD) }\end{array}$ & $p$ value \\
\hline Total & $50(100.0)$ & $12(24.0)$ & $38(76.0)$ & - \\
\hline Age, years & $42.1(28.6)$ & $40.2(23.5)$ & $42.7(30.3)$ & $0.794^{c}$ \\
\hline Female sex & $23(46.0)$ & $4(33.3)$ & $19(50.0)$ & $0.498^{\mathrm{a}}$ \\
\hline \multicolumn{5}{|l|}{ IBD diagnosis } \\
\hline Previous to Aeromonas isolation & $7(14.0)$ & $7(58.3)$ & - & - \\
\hline Posterior to Aeromonas isolation & $5(10.0)$ & $5(41.7)$ & - & - \\
\hline \multicolumn{5}{|c|}{ Comorbidities at the moment of Aeromonas fecal isolation } \\
\hline Arterial hypertension & $14(28.0)$ & $3(25.0)$ & $11(28.9)$ & $1.000^{\mathrm{b}}$ \\
\hline Dyslipidemia & $7(14.0)$ & $1(8.3)$ & $6(15.8)$ & $1.000^{\mathrm{b}}$ \\
\hline Diabetes & $4(8.0)$ & $1(8.3)$ & $3(7.9)$ & $1.000^{\mathrm{b}}$ \\
\hline Chronic renal failure & $3(6.0)$ & $0(0.0)$ & $3(7.9)$ & $1.000^{\mathrm{b}}$ \\
\hline Cirrhosis & $2(4.0)$ & $0(0.0)$ & $2(5.3)$ & $1.000^{\mathrm{b}}$ \\
\hline Cancer & $5(10.0)$ & $0(0.0)$ & $5(13.2)$ & $0.319^{b}$ \\
\hline Transplant & $6(12.0)$ & $1(8.3)$ & $5(13.2)$ & $1.000^{\mathrm{b}}$ \\
\hline \multicolumn{5}{|c|}{ Ongoing drugs at the moment of Aeromonas fecal isolation } \\
\hline PPI & $18(36.0)$ & $5(41.7)$ & $13(34.2)$ & $0.735^{\mathrm{b}}$ \\
\hline Chemotherapy & $5(10.0)$ & $0(0.0)$ & $5(13.2)$ & $0.319^{b}$ \\
\hline Immunosuppressed patients & $13(26.0)$ & $7(58.3)$ & $6(18.8)$ & $0.073^{b}$ \\
\hline \multicolumn{5}{|l|}{ Immunosuppressant drugs } \\
\hline AZA & $4(8.0)$ & $3(25.0)$ & $1(2.6)$ & $0.038^{\mathrm{b}}$ \\
\hline Topical or systemic steroids & $6(12.0)$ & $4(33.3)$ & $2(5.3)$ & $0.024^{b}$ \\
\hline Calcineurin inhibitors & $6(12.0)$ & $1(8.3)$ & $5(13.2)$ & $0.294^{b}$ \\
\hline Biologic therapy (anti-TNF) & $1(2.0)$ & $1(8.3)$ & $0(0.0)$ & $0.240^{\mathrm{b}}$ \\
\hline Previous abdominal surgery & $12(24.0)$ & $1(8.3)$ & $11(28.9)$ & $0.248^{b}$ \\
\hline
\end{tabular}

AZA, azathioprine; IBD, Inflammatory bowel disease; PPI, proton pump inhibitors; SD, standard deviation; ${ }^{\text {a }} \mathrm{X}^{2}$ test; ${ }^{b}$ Fisher Test; ${ }^{C}$ Independent sample Student's $t$ test.

routinely used methods). Symptoms presented at the time of Aeromonas isolation differ among both groups, with IBD patients presenting more frequently with bloody diarrhea ( 83.3 vs. $10.5 \%, p<0.001)$ and abdominal pain ( 75.0 vs. $34.2 \%, p=0.032$ ). The presence of fever was more common among patients without IBD ( 0.0 vs. $34.2 \%, p=0.022)$. IBD patients were more frequently under AZA (25.0 vs. $2.6 \%, p=0.038)$ and systemic or topical steroids ( 33.3 vs. $5.3 \%, p=0.024$ ) when compared with non-IBD patients. Immunosuppressive therapy with calcineurin inhibitors was more often used in non-IBD patients ( 8.3 vs. $13.2 \%, p=0.294$ ).

The majority of patients presented a mild-moderate Aeromonas infection with a proportionally higher tendency for severe episodes in IBD patients (27.3 vs. $13.5 \%, p>0.05)$. There were $8(16.7 \%)$ severe cases, 7 of which concerned immunocompromised patients. Nineteen patients $(41.7 \%$ were IBD and $36.8 \%$ non-
IBD) needed to be admitted to the hospital for management of severe infection and symptomatic control in moderate cases.

Concerning the treatment of the acute episode, IBD patients were more frequently submitted to antibiotics ( 83.3 vs. $36.8 \%, p=0.013$ ), and quinolones were the most frequently used class in both (36\% overall). Only IBD patients were treated with systemic or topical steroids ( 33.3 vs. $0.0 \%, p=0.002$ ), and all of these patients were also under antibiotics. Four (8\%) Aeromonas-resistant strains were identified (3 [7.9\%] in non-IBD vs. 1 [8.3\%] in IBD). Other fecal bacteria were identified only in 4 non-IBD patients (10.5\%): 3 children, two 1-year-olds and one 8-year-old, presented Campylobacter jejuni, and a 73-year-old patient presented also with Salmonella. All patients progressed favorably with no deaths observed. 
Table 2. Clinical presentation features in IBD and non-IBD patients

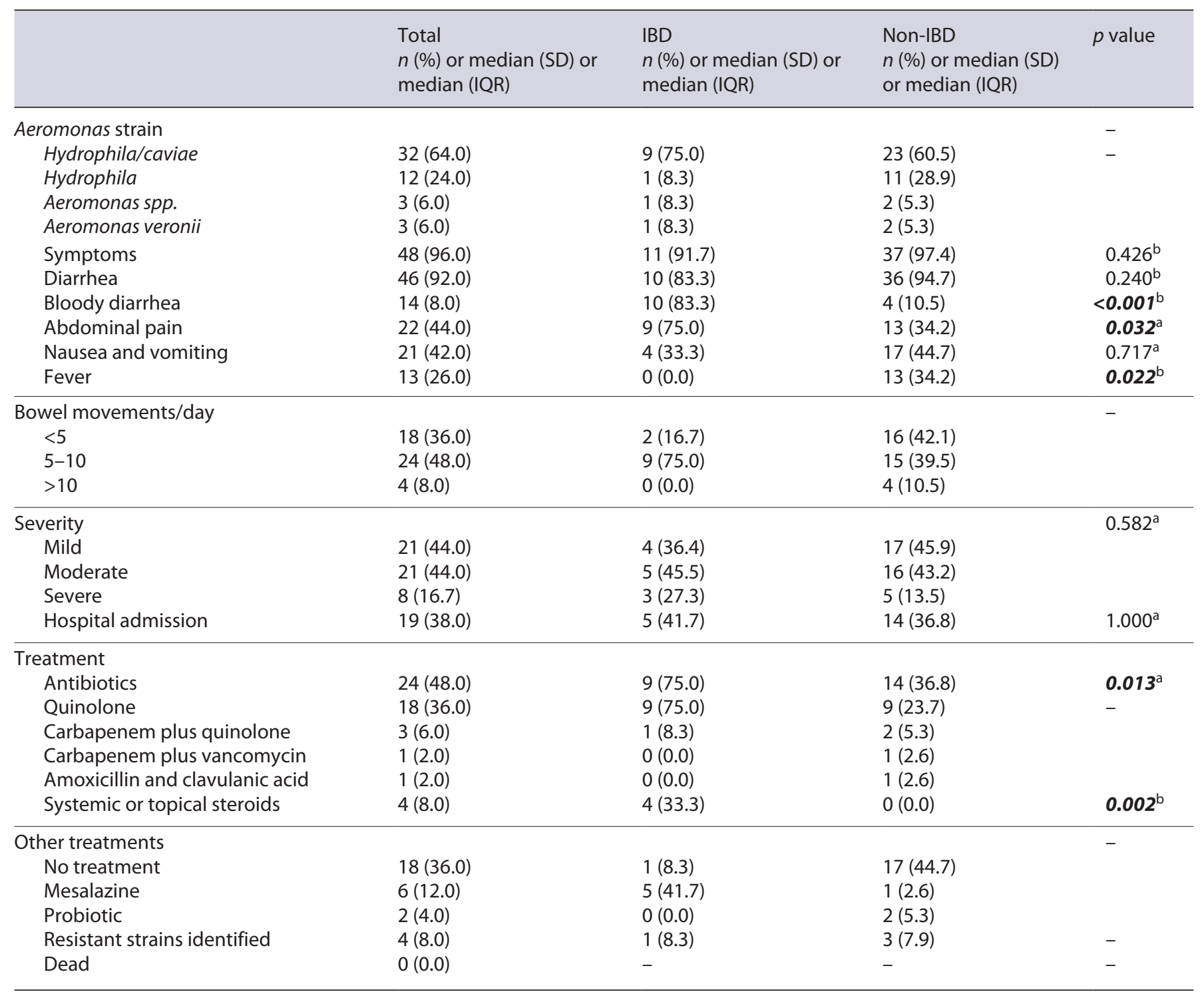

IBD, inflammatory bowel disease; IQR, interquartile range; SD, standard deviation; ${ }^{a} X^{2}$ test; ${ }^{b}$ Fisher test; ${ }^{c}$ Independent sample Student's $t$ test.

IBD Diagnosis and Aeromonas Infection

Clinical characteristics of IBD patients and Aeromonas infection are presented in Table 3. From the IBD patient subgroup, 7 had the diagnosis of IBD previously and 5 after the Aeromonas isolation. From the latter, only 1 had the infection and subsequent diagnosis of IBD at pediatric age (patient 8 , Table 3 ).

From those with a previously established diagnosis of IBD, 3 were UC patients and $4 \mathrm{CD}$ patients (Table 3 ). Only 1 patient with $C D$ was under combined therapy with infliximab and AZA (patient 4, Table 3), and the remaining were under AZA monotherapy at the time of Aeromonas isolation. UC patients were under mesalamine. One patient (patient 9, Table 3) was under tacrolimus due to a previous liver transplant. Five patients were treated with antibiotics, and 2 of them simultaneously with systemic steroids. One patient was treated only with topical steroids. Three patients needed hospital admission, with one requiring ganciclovir treatment due to concomitant histological features of CMV on colonic biopsy (patient 5, 


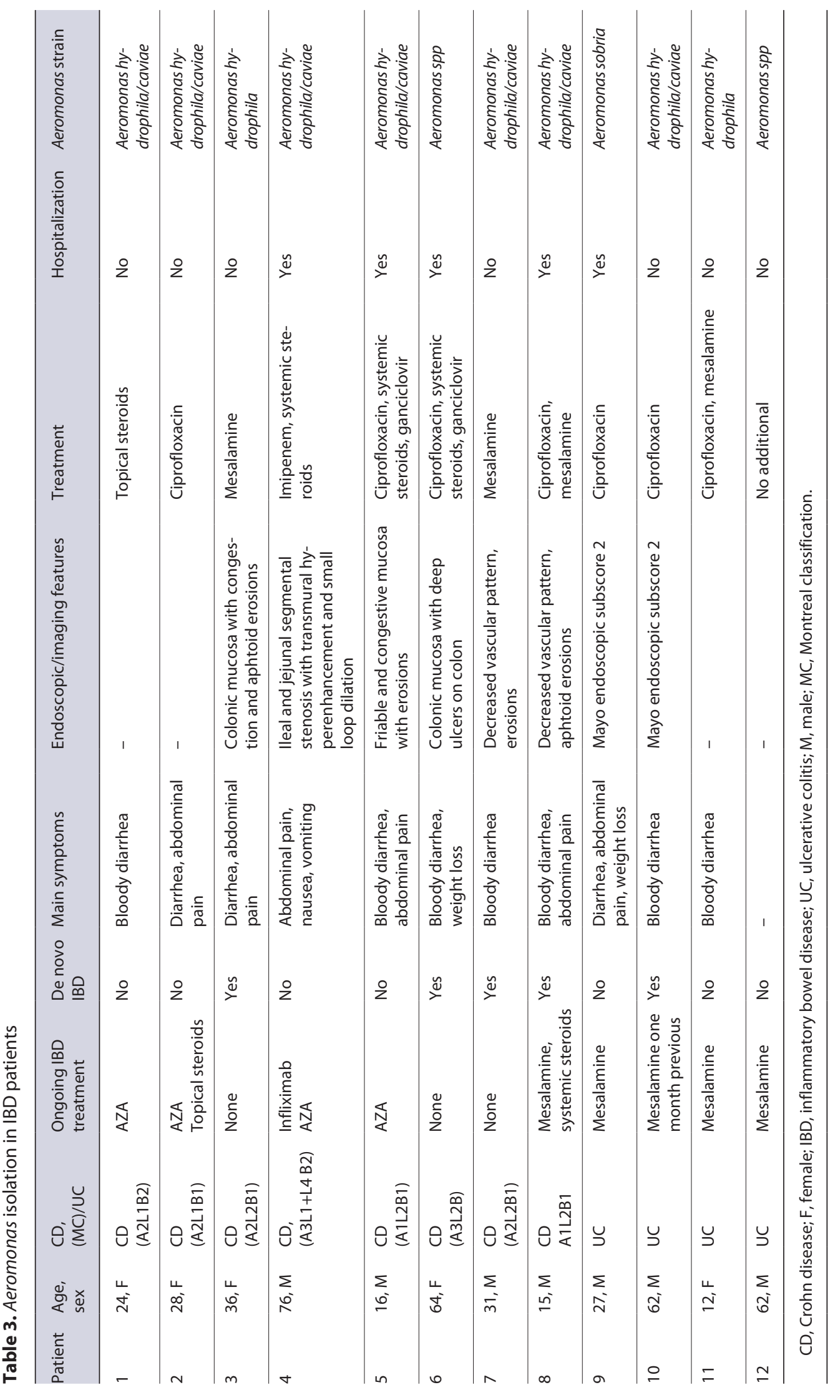


Table 3). The only patient under infliximab presented with intestinal sub-occlusion with a quinolone-resistant A. hydrophila/caviae isolation. All patients progressed favorably, and none needed to escalate IBD therapy after the Aeromonas acute episode. Seven patients were submitted to endoscopic evaluation. However, histological data was compatible with IBD, with no other specific features. Immediately after the acute episode, only clinical and analytical data were used to assess the remission, namely the symptoms reported by the patients, CRP, and calprotectin.

Concerning the 5 patients with a diagnosis of IBD after the episode of Aeromonas isolation, 4 of them were diagnosed with colonic CD and 1 with UC. Two of them were admitted to the hospital with 1 showing simultaneous histological features of CMV infection on colonic biopsy (patient 6, Table 3), being treated with antibiotics, systemic steroids, and ganciclovir. The other 3 received the IBD diagnosis in an ambulatory setting due to the persistence of chronic diarrhea in which Aeromonas was isolated in the first stool culture requested for the workup. From this subgroup of patients with de novo IBD diagnosis, 2 required posterior escalation therapy to infliximab (patients 6 and 10, Table 3).

\section{Discussion/Conclusion}

The pathogenic role of Aeromonas in human enterocolitis is still controversial as is the association of Aeromonas infection with IBD development or as a flare trigger. To our knowledge, a few case reports have been published, with only 2 similar case series available $[7,8]$.

The global prevalence of Aeromonas gastrointestinal infection ranges from 2 to $88 \%$ and carriage status in healthy individuals from 1 to $45 \%$ [7]. Stool isolation rates differ depending, among others, on geography, food habits, and isolation methods [20]. The prevalence of infection in developed countries ranges from 0.8 to $7.4 \%$ and carriage rate from 0 to $4 \%$ [20], indicating a possible higher prevalence in developing countries. Although no specific data exists for Portugal, we had a relatively low number of Aeromonas stool isolation considering the period covered. The evolution of Aeromonas detection methods through the years may have a role in it, since the majority $(56 \%)$ of our isolates were identified between 2014 and 2019, coinciding with the introduction of mass spectrometry methods. In this study $(n=50), 2$ patients were asymptomatic carriers (4\%), concordant with the reported carriage rate in healthy individuals in developed countries [20].
The reports of the most predominant clinical species of Aeromonas have changed over the years. Improved molecular methods led to the conclusion that $95.4 \%$ of the strains associated with the clinical disease were A. caviae (37.3\%), A. veronii (23.5\%), A. dhakensis (21.5\%), and A. hydrophila (13.1\%) [21]. In our study, the 3 identified species are concordant with the most associated with clinical disease in other studies $[7,8]$. Nevertheless, since $A$. dhakensis cannot be identified by the biochemical methods and mass spectrometry used in our laboratory, we cannot exclude that there might be a misidentification as A. caviae, A. hydrophila, or A. veronii. Although our data reinforce the predilection of this finding in non-IBD patients (96.2\%), we have interestingly shown higher isolation of A. hydrophila. This could be explained by the higher number of patients under 18 years old and different geographical factors. It should, however, be kept in mind that the frequency of each strain differs according to the country. In our study, no relation was found between the strains and severity of the clinical manifestations.

When compared with a recent similar study performed in a tertiary hospital in Spain $(n=98)$ [8], the mean age of our population was lower (42 vs. 62 years-old) as well as the proportion of female sex ( $46 \mathrm{vs.} 51 \%$ ). This difference can be explained mainly by the fact that only adult patients were involved in the Spanish study. On the other hand, we presented a higher percentage of isolates in patients with previous IBD diagnosis ( $14 \mathrm{vs.} 11 \%$ ) with very similar cases of CD (8 vs. 7 patients) and an equal number of UC patients $(n=4)$.

The main comorbidities found in our group of patients were malignancies (10\%), pharmacological immunosuppression (34\%), and liver diseases (4\%). Aeromonas is known to cause gastrointestinal symptoms in both immunocompetent and immunocompromised individuals with predisposing factors reported, such as diabetes, hematological malignancies, or hepatobiliary diseases [20]. Overall, the severity of the infection in our population was mainly mild-moderate with $17 \%$ severe. The percentage of severe infection was greater in IBD patients (27.3 vs. $13.5 \%$ ), also reported by others [7]. Of the 5 non-IBD patients that presented with severe infection, 2 were undergoing chemotherapy, 2 had previous abdominal surgery, and the last was an HIV patient with no antiretroviral therapy adherence. The reported mortality rate can reach $30 \%$ in the set of Aeromonas' bacteremia [21]. Fortunately, there were no reported deaths attributed to the infection in our study.

The antibiotic susceptibility profile for Aeromonas does not appear to have changed substantially [22]. In the
Pereira Guedes/Alves Silva/Neves/Falcão/ Costa/Lago/Pedroto/Salgado 
present study, only 4 isolates were resistant to antibiotics usually active against aeromonads, according to EUCAST breakpoints [23]. Two patients had a strain resistant to ciprofloxacin and cotrimoxazole, another patient to cotrimoxazole, and the last one to ciprofloxacin. There was no identified resistance to carbapenems, a fortunate sign regardless of the reports describing an increased Aeromonas resistance to the latter [24]. Resistant strains were more common in non-IBD patients (75 vs. $25 \%$ ). This could be explained by the fact that the mean age of nonIBD patients was higher, which usually implies a significantly higher exposure to antibiotics and previous hospital admissions.

In our analysis, IBD patients represented $24 \%$ of our population with a predominance of male sex and a tendency for younger age when compared to non-IBD patients. In the previous series, IBD patients represented $11-14 \%$ of all Aeromonas-positive patients with the same age trend $[7,8]$. Symptomatic Aeromonas infection was seen in almost all patients (96\%). Distinctive symptoms between the two groups were the presence of bloody diarrhea and abdominal pain which was significantly more common in IBD patients. This was in line with previous findings suggesting that a colonic involvement in the vast majority of IBD might explain the high rates of bloody diarrhea in these patients [7].

A higher proportion of IBD patients presented a severe clinical infection which followed the trend of previous studies [7]. Three IBD patients presented a more severe disease: one was under tacrolimus after liver transplant due to primary sclerosing cholangitis; the other patient was under combined therapy with infliximab and AZA; finally, a 64-year-old female with de novo $\mathrm{CD}$ and severe endoscopic features with concomitant CMV colitis. Almost half of non-IBD patients present a mild disease, which is a very similar result compared to the $44 \%$ previously reported $[7,16]$. IBD population significantly needed more antibiotic therapy and steroids, following the trend of higher severity of infection. This might be explained by the lower threshold to antibiotic therapy in patients with IBD, namely in immunocompromised, regardless of clinical, analytical, and endoscopic features.

Regarding the place of Aeromonas infection in the natural history of the disease, the scarcely reported literature on the subject poses it as a potential trigger to flare and for the de novo IBD diagnosis. In our study, from those with IBD, 7/12 were diagnosed previously to Aeromonas isolation. A role for Aeromonas as a trigger to IBD flare was previously reported in a patient diagnosed with mild ulcerative proctitis, who presented a severe colitis refractory to steroid therapy with favorable evolution under antibiotic therapy directed to the isolated Aeromonas [16]. On the other hand, other reports had postulated a putative role of Aeromonas infection for the development of de novo IBD diagnosis $[7,12]$. It remains under discussion if the infection prompts IBD development or naturally unmasks an underlying disease with previous subclinical activity. The mechanisms inherent to these interrelationships are unknown, but Aeromonas-associated intestinal dysbiosis could possibly lead to reduced bacterial diversity and, in those genetically susceptible, result in IBD onset. In our population, we also found concomitant CMV infection (Table 3, patient 6). Giving the epidemiology of CMV as a flare-causing pathogen in IBD, the endoscopic features (deep ulcers on colon) and the significant prevalence of Aeromonas carriage status, it is plausible that the Aeromonas isolated was not responsible for causing the disease.

In our population, we observed the subsequent diagnosis of IBD in 5/12 patients after Aeromonas infection. Lobatón et al. [7] also described 2 cases of diarrhea and abdominal pain with Aeromonas detection simultaneously to CD diagnosis. Similarly, more than 30 years ago, an association was proposed between Aeromonas infection and the new onset of 3 cases of UC [19].

Although it represents one of the few studies relating Aeromonas infection and IBD patients, there are some limitations to address. The retrospective character of the study, data retrieval from a unicentric microbiology database, and the loss of 3 patients due to insufficient clinical information might bias the interpretation of our results. It is important to mention that only 7 IBD patients with flares were submitted to endoscopic evaluation, which, to some extent, could compromise the conclusion. Also, the analysis of the time between Aeromonas isolation and the first signs of IBD would be important in the evaluation of the possible causality between the two diseases in future larger studies. It is important to mention the heterogeneity of the control group, mainly the inclusion of pediatric patients that could compromise the comparisons that were made. The reduced sample and the bias to request stool culture mainly in symptomatic patients do not allow us to infer about the overall and ecological scenario of Aeromonas identification in our population.

In conclusion, Aeromonas infection appears to play an important role in IBD activity. This infection might contribute as one more piece in the interactome unsolved puzzle for IBD. Our results reinforce that Aeromonas in- 
fection can be a trigger for IBD flare or de novo IBD diagnosis, supporting the importance of fecal culture analysis. Our results allying with the lack of data on Aeromonas infection and IBD might indicate an overlook of this infection.

\section{Statement of Ethics}

The authors declare that the procedures followed were in accordance with the regulations of the relevant clinical research ethics committee and with those of the Code of Ethics of the World Medical Association (Declaration of Helsinki).

The authors declare that they have followed the protocols of their work center on the publication of patient data.

The authors declare that no patient data appear in this article.

\section{Conflict of Interest Statement}

The authors have no conflicts of interest to declare.

\section{Funding Sources}

No funding.

\section{Author Contributions}

T.P.G. and J.A.S. equally contributed to the manuscript. T.P.G. and M.S. conceived and designed the study. T.P.G., J.A.S., S.N., D.F. collected, analyzed, and interpreted data. P.C., P.L., I.P., and M.S. performed critical review of the manuscript.

\section{References}

1 Zhou Y, Yu L, Nan Z, Zhang P, Kan B, Yan D, et al. Taxonomy, virulence genes and antimicrobial resistance of Aeromonas isolated from extra-intestinal and intestinal infections. BMC Infect Dis. 2019 Feb;19(1):158.

2 Bhowmick UD, Bhattacharjee S. Bacteriologi$\mathrm{cal}$, clinical and virulence aspects of aeromonas-associated diseases in humans. Pol J Microbiol. 2018 Jun;67(2):137-49.

3 Morgan DR, Johnson PC, DuPont HL, Satterwhite TK, Wood LV. Lack of correlation between known virulence properties of Aeromonas hydrophila and enteropathogenicity for humans. Infect Immun. 1985 Oct; 50(1):62-5.

4 Tomás JM. The main Aeromonas pathogenic factors. ISRN Microbiol. 2012 Sep;2012: 256261.

5 Ko WC, Lee HC, Chuang YC, Liu CC, Wu JJ. Clinical features and therapeutic implications of 104 episodes of monomicrobial Aeromonasbacteraemia. JInfect. 2000 May;40(3):26773.

6 von Graevenitz A. The role of Aeromonas in diarrhea: a review. Infection. 2007 Apr;35(2): 59-64.

7 Lobatón T, Hoffman I, Vermeire S, Ferrante M, Verhaegen J, Van Assche G. Aeromonas species: an opportunistic enteropathogen in patients with inflammatory bowel diseases? A single center cohort study. Inflamm Bowel Dis. 2015 Jan;21(1):71-8.

8 Elorza A, Rodríguez-Lago I, Martínez P, Hidalgo A, Aguirre U, Cabriada JL. Gastrointestinal infection with Aeromonas: incidence and relationship to inflammatory bowel disease. Gastroenterol Hepatol. 2020 Dec;43(10): $614-9$.
9 de Souza HS, Fiocchi C, Iliopoulos D. The IBD interactome: an integrated view of aetiology, pathogenesis and therapy. Nat Rev Gastroenterol Hepatol. 2017 Dec;14(12):739-49.

10 Baumgart DC, Carding SR. Inflammatory bowel disease: cause and immunobiology. Lancet. 2007 May;369(9573):1627-40.

11 Orel R, Kamhi Trop T. Intestinal microbiota, probiotics and prebiotics in inflammatory bowel disease. World J Gastroenterol. 2014 Sep;20(33):11505-24.

12 Lobatón T, Domènech E. Bacterial Intestinal Superinfections in Inflammatory Bowel Diseases Beyond Clostridum difficile. Inflamm Bowel Dis. 2016 Jul;22(7):1755-62.

13 Barnich N, Carvalho FA, Glasser AL, Darcha C, Jantscheff P, Allez M, et al. CEACAM6 acts as a receptor for adherent-invasive E. coli, supporting ileal mucosa colonization in Crohn disease. J Clin Invest. 2007 Jun;117(6): 1566-74.

14 Nishikawa J, Kudo T, Sakata S, Benno Y, Sugiyama T. Diversity of mucosa-associated microbiota in active and inactive ulcerative colitis. Scand J Gastroenterol. 2009;44(2):180-6.

15 Castaño-Rodríguez N, Kaakoush NO, Lee WS, Mitchell HM. Dual role of Helicobacter and Campylobacter species in IBD: a systematic review and meta-analysis. Gut. $2017 \mathrm{Feb}$; 66(2):235-49.

16 Baliellas Comellas C, Xiol Quingles X, Castellote Alonso J, Torras Torra J. [Severe occurrence of idiopathic ulcerative colitis caused by Aeromonas sobria]. Rev Esp Enferm Dig. 1991 Jun;79(6):442-3.
17 de Sola Earle C, Montiel Quezel-Guerraz N, Hidalgo Rojas L, Sánchez Cantos A, García Alegría J. Gastroenteritis aguda grave por Aeromonas en paciente colectomizado por enfermedad de Crohn. Rev Esp Enferm Dig. 1997 Jan;89(1):48-50.

18 Ahishali E, Pinarbasi B, Akyuz F, Ibrisim D, Kaymakoglu S, Mungan Z. A case of Aeromonas hydrophila enteritis in the course of ulcerative colitis. Eur J Intern Med. 2007 Sep; 18(5):430-1.

19 Willoughby JM, Rahman AF, Gregory MM. Chronic colitis after Aeromonas infection. Gut. 1989 May;30(5):686-90.

20 Igbinosa IH, Igumbor EU, Aghdasi F, Tom M, Okoh AI. Emerging Aeromonas species infections and their significance in public health. ScientificWorldJournal. 2012;2012:625023.

21 Fernández-Bravo A, Figueras MJ. An Update on the Genus Aeromonas: Taxonomy, Epidemiology, and Pathogenicity. Microorganisms. $2020 \mathrm{Jan} ; 8(1): 129$.

22 Janda JM, Abbott SL. The genus Aeromonas: taxonomy, pathogenicity, and infection. Clin Microbiol Rev. 2010 Jan;23(1):35-73.

23 EUCAST. Clinical breakpoints and dosing of antibiotics [Internet]. [cited $2021 \mathrm{Feb} 27$ ]. Available from: https://www.eucast.org/clinical_breakpoints/

24 Sinclair HA, Heney C, Sidjabat HE, George NM, Bergh H, Anuj SN, et al. Genotypic and phenotypic identification of Aeromonas species and CphA-mediated carbapenem resistance in Queensland, Australia. Diagn Microbiol Infect Dis. 2016 May;85(1):98-101. 